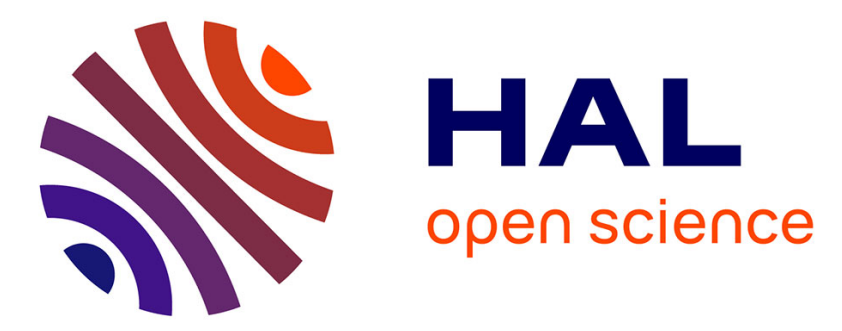

\title{
Experimental performances study of a transportable GC-PID and two thermo-desorption based methods coupled to FID and MS detection to assess BTEX exposure at sub-ppb level in air C. Liaud, N.T. Nguyen, R. Nasreddine, S. Le Calvé
}

\section{To cite this version:}

C. Liaud, N.T. Nguyen, R. Nasreddine, S. Le Calvé. Experimental performances study of a transportable GC-PID and two thermo-desorption based methods coupled to FID and MS detection to assess BTEX exposure at sub-ppb level in air. Talanta, 2014, 127, pp.33-42. 10.1016/j.talanta.2014.04.001 . hal-02308194

\author{
HAL Id: hal-02308194 \\ https://hal.science/hal-02308194
}

Submitted on 9 Dec 2020

HAL is a multi-disciplinary open access archive for the deposit and dissemination of scientific research documents, whether they are published or not. The documents may come from teaching and research institutions in France or abroad, or from public or private research centers.
L'archive ouverte pluridisciplinaire HAL, est destinée au dépôt et à la diffusion de documents scientifiques de niveau recherche, publiés ou non, émanant des établissements d'enseignement et de recherche français ou étrangers, des laboratoires publics ou privés. 


\title{
Experimental performances study of a transportable GC-PID and two thermo- desorption based methods coupled to FID and MS detection to assess BTEX exposure at sub-ppb level in air
}

\author{
C. Liaud, N.T. Nguyen ${ }^{\dagger}$, R. Nasreddine and S. Le Calvé * \\ Institut de Chimie pour les Procédés, l'Energie, l'Environnement et la Santé (ICPEES, UMR \\ 7515 CNRS/UdS), 25 rue Becquerel, 67087 Strasbourg Cedex 02, France \\ * Corresponding author. Fax: (0033)(0)3 688504 02. E-mail address: slecalve@unistra.fr \\ ${ }^{\dagger}$ Current address : Laboratoire de Spectrométrie de Masse des Interactions et des Systèmes (LSMIS, \\ UMR 7140),University of Strasbourg, Strasbourg, France
}

\begin{abstract}
BTEX compounds are of particular interest, above all benzene because it is a carcinogenic compound for which guideline value in European indoor environments is set to $1.6 \mathrm{ppb}$. Therefore, the detection of such relatively low value requires the use of particularly sensitive analytical techniques. Several existing chromatographic techniques, such as fast and transportable Gas Chromatograph with Photoionization Detection (GC-PID) or sedentary chromatographic-based techniques equipped with a thermo-desorption device (ATD) and coupled to either Flame Ionization Detection (FID) or Mass Spectrometry (MS), can quantify benzene and its derivatives at such low levels.

These instruments involve different injection modes, i.e. on-line gaseous sampling or thermodesorption of adsorbent tubes spiked with liquid or gas samples. In this study, the performances of 3 various analytical techniques mentioned above were compared in terms of sensitivity, linearity, accuracy and repeatability for the 6 BTEX. They were also discussed related to their analyses time consumption or transportability. The considered analytical techniques are ATD-GC-FID, ATD-GCMS where both Full scan and SIM mode were tested and a transportable GC-PID. For benzene with on-line injection, Limits of Detection (LOD) were significantly below the European guideline with values of 0.085, 0.022, 0.007 and $0.058 \mathrm{ppb}$ for ATD-GC-FID, ATD-GC-MS in full scan mode, ATDGC-MS in SIM mode and transportable GC-PID, respectively. LOD obtained with adsorbent tubes spiked with liquid standards were approximately the same order of magnitude.
\end{abstract}




\section{Keywords}

BTEX, Analytical method, GC-PID, GC-MS, GC-FID, Thermo-desorption

\section{Highlights}

- Fast GC-PID, GC-FID and GC-MS applied to BTEX analysis are compared

- The performances of two thermo-desorption injection modes are evaluated

- Calibrations at sub-ppb level from cartridge spiking are more appropriated

- For higher concentrations, gaseous calibrations agree with cartridge spiking

- All the detection limits are significantly below the benzene European guideline

\section{Introduction}

Both outdoor and indoor airs contain traces of many organic species and their analysis is then an attractive analytical challenge. Among these organic air pollutants, BTEX (Benzene, Toluene, Ethylbenzene, o-, $\mathrm{m}$ - and p-Xylenes) figure heavily in estimation of air quality. Their outdoor major sources are automotive exhausts and industrial processes [1-3]. In indoor environments, a major part of BTEX emissions is also directly related to indoor activities such as cooking, heating, smoking, cleaning, and includes also emissions from building materials, varnishes, paints and solvents etc.[4,5]. The total indoor BTEX concentrations results from indoors emissions, but also from outdoor concentrations, depending on the air exchange processes between inside and outside environments $[3,6]$.

Measurements of the concentration level of BTEX in air is necessary for many reasons in order to determine the health effects $[7,8]$, the sources of pollution $[9,10]$, the spatial and seasonal variations $[11,12]$ or the compliance with monitoring thresholds [9]. For instance, the European Commission has established objectives to reach for numerous pollutants and has fixed for benzene a limit of exposure of $5 \mu \mathrm{g} \cdot \mathrm{m}^{-3}$ (= $1.6 \mathrm{ppb}$ ) on an average period of one year. In addition, the International Agency for Research on Cancer (IARC) has classified Benzene as a carcinogenic and mutagenic substance of group 1 [8]. Some studies deal with the chemical behavior of these compounds in the human body or in the environment, especially air and water, whereas other aim to develop advanced analytical techniques to measure concentrations levels in different matrixes [13,14].

These analytical techniques mostly based on a sampling step followed by gas chromatography analysis enable to quantify the BTEX concentrations in air $[15,16]$. There are two types of analytical techniques to measure BTEX concentrations. First, the on-line measurement techniques allow direct access to real-time air concentration levels with time resolution varying usually between several 
seconds and 30 minutes [17-24]. Such analyzers are less common and need to be light enough to be transported to the sampling site. Most of them require gas cylinder for on-site calibration. The off-line analytical methods firstly require a step of air sampling on site using multiple well-known sampling methods [25] such as adsorbent cartridges using active or passive sampling [11,25,26], canisters [27,28], bags [29]. Sample preparation and analysis based on heavy equipments are then performed in the laboratory [30]. These methods are more time-consuming but enable to achieve multi-pollutants analysis [31-34], i.e. other VOCs families can be also monitored.

The BTEX concentrations are often low in air explaining why analytical techniques have to be more sensitive and/or specific to target compounds. To increase sensitivity a preliminary concentration step consisting in cryofocusing is often used $[15,16]$. This concentration step combined to adapted detectors allows the detection of BTEX below the ppb level [33-36]. To monitor BTEX at low ppb level, numerous detectors are available but the most commonly used, although they are not specific, are the Ionization Flame Detector (FID) and Mass spectrometry (MS) [31,33]. However, a more specific detector such as Photoionization Detector (PID) is also very widespread [21,36,37].

In this study, we compared the performances of several analysis techniques applied to the BTEX measurements either in highly controlled gas mixtures or in sorbent tubes spiked with gaseous or liquid standards. One technique is a transportable Gas Chromatograph equipped with a Photoionization Detector (GC-PID). The two others are Automated Thermal Desorbers supplied either with a Gas Chromatograph and a Flame Ionization Detector (ATD-GC-FID) or a Gas Chromatograph coupled with a Mass Spectrometer Detector (ATD-GC-MS). For the first time in this work, these techniques will be compared on several performances criteria such as limit of detection (LOD), accuracy, time required for a complete analysis. This study also includes a comparison of analytical performances obtained with the two injection modes available on the ATD device: on-line and 2stage-desorb, which consist in desorption of adsorbent tubes.

\section{Materials and methods}

\subsection{Chemicals and materials}

On-line calibration curves and sorbent tubes gas spiking were done with certified gas standard BTEX mixture obtained from Messer (Puteaux, France). The initial concentration for each BTEX was $100 \mathrm{ppb}$ with $10 \%$ uncertainty. Nitrogen (99.999\%), used for dilution, was also obtained from Messer (Puteaux, France). Mass flow controllers from Bronkhorst (Montigny les Cormeilles, France) were used for dilutions: dynamic range within $0-5 \mathrm{~L} \mathrm{~min}^{-1}$ for nitrogen and within either $0-30 \mathrm{~mL} \mathrm{~min}^{-1}$ or 0$100 \mathrm{~mL} \mathrm{m^{-1 }}$ for BTEX mixture. The mass flow meters uncertainty on full scale was $0.1 \%$ whereas accuracy on measured value was $0.5 \%$. 
Calibration curves with sorbent tubes liquid spiking were performed with a $100 \mathrm{mg} \mathrm{L}^{-1}$ standard BTEX mixture with $0.5 \%$ uncertainty obtained from LGC Standards (Molsheim, France). Methanol for gas chromatography (Methanol absolute LC-MS) with a purity $\geq 99.95 \%$ was obtained from Biosolve (Dieuze, France). PerkinElmer stainless steel tubes (6.35 mm external diameter, $88.9 \mathrm{~mm}$ long) with Carbopack ${ }^{\mathrm{TM}}$ B adsorbent were obtained from Supelco (Bellefonte, PA, USA). These tubes are packed with approximately $200 \mathrm{mg}$ of Carbopack ${ }^{\mathrm{TM}} \mathrm{B}$ with granulometry of $60 / 80 \mathrm{mesh}$. This adsorbent was chosen because, for BTEX, it is suggested to use graphitized carbon black with a medium specific surface area of $100 \mathrm{~m}^{2} \mathrm{~g}^{-1}$. In addition, these adsorbent are hydrophobic which allow sampling high air volumes even if relative humidity is high [38-40]. Helium (99.9995\%) and air (99.999\%) for gas chromatography and detectors were also obtained from Messer. Hydrogen production for detectors was produced by a hydrogen generator HyGen 200 from CLAIND (Lenno, Italy).

\subsection{Analytical instrumentation}

Three analytical methodologies were evaluated:

- ATD-GC-MS: Automatic Thermal Desorption (ATD) with capillary gas chromatography (GC) coupled with a Mass Selective Detector (MSD)

- ATD-GC-FID: Automatic Thermal Desorption (ATD) with capillary gas chromatography (GC) coupled with Ionization Flame Detector (FID)

- Transportable GC-PID: GC coupled to Photoionization detection.

The first chromatograph was a 6890N Network GC System interfaced with a 5973 Network MSD, both from Agilent Technologies (Agilent Technologies, Santa Clara, CA, USA), the capillary column was an Agilent DB-5ms, $60 \mathrm{~m}$ x $0.25 \mathrm{~mm}$ ID x $1 \mu \mathrm{m}$ (film thickness). The MS detector used provided acquisition in full-scan mode or Selected Ion Monitoring (SIM) mode. Electron impact spectra were obtained at electron energy of $70 \mathrm{eV}$. The temperatures of the GC-MS interface and source were both set to $200{ }^{\circ} \mathrm{C}$. Mass spectral data were acquired over a mass range of 50-600 amu for the full-scan mode. The qualitative identification of targeted compounds was based on the match of the retention times. Quantification was conducted by the external standard method and on extracted ions. To quantify BTEX in Single Ion Monitoring (SIM) mode, the chosen precursor ions were $78 \mathrm{~m} / \mathrm{z}$ (mass to charge ratio) for benzene and $91 \mathrm{~m} / \mathrm{z}$ for the other evaluated compounds. The identification was based on retention time of these quantified ions in addition to ion ratios with qualifiers ions (at m/z 51, 65 and 106 for benzene, toluene and ethylbenzene, xylenes respectively). The dwell-time was chosen at $100 \mathrm{~ms}$.

The second system was a Perkin Elmer gas chromatograph Clarus ${ }^{\circledR} 580$ with a dual column system and twins FID. In this study, only the first capillary column, Perkin Elmer Phase Elite 1, $60 \mathrm{~m}$ x $0.25 \mathrm{~mm}$ ID x $0.25 \mu \mathrm{m}$ (film thickness), and one FID was of concern. The detector operated with a hydrogen gas flow of $40 \mathrm{~mL} \mathrm{m^{-1 }}$ and an air gas flow of $400 \mathrm{~mL} \mathrm{~min}^{-1}$, attenuation was fixed to -6 
and flame temperature to $250^{\circ} \mathrm{C}$. BTEX identification was based on the match of the retention times. Quantification was conducted by the external standard method. The nature of the columns used for either ATD-GC-MS or ATD-GC-MS is different because we took those available in the laboratory. In addition, the nature of the phase is a little bit different but the elution order of BTEX remained the same.

The third studied system is a transportable GC coupled with a Photoionization Detector (PID). The gas chromatograph Series 8900 BTEX Analyzer $(13.6 \mathrm{~kg}, 44.7 \mathrm{~cm}$ x $41.2 \mathrm{~cm}$ x $23.5 \mathrm{~cm})$ from Baseline-MOCON (Lyons, CO, USA) is equipped with a high-sensitivity PID and is specific to volatile organic compounds such as BTEX. It allows, according to constructor, high sensitivity for BTEX compounds and Limits Of Detection (LOD) are near from $0.05 \mathrm{ppb}$ for benzene and $<0.1 \mathrm{ppb}$ for toluene, ethylbenzene, and xylenes. The 6 BTEX in the gas sample were separated using a megabore type fused silica column MXT-WAX (40 m x $0.53 \mathrm{~mm}$ IDx $1 \mu \mathrm{m})$.

\subsection{On-line analysis}

With the two ATD-equipped systems, the sampling step was performed during 20 min with a sampling flow of $25 \mathrm{~mL} \mathrm{~min}^{-1}$ (pumping device Laboport ${ }^{\circledR}$ from KNF Lab, Trenton, NJ, USA). This step allows BTEX gas flow to be concentrated onto the cold trap (Air monitoring trap, Perkin Elmer). Each sample was drawn through a Nafion ${ }^{\circledR}$ dryer who is suitable for the measurement of hydrocarbons. The cold trap (Air monitoring Trap, Perkin Elmer) was maintained at -30 C. After a short primary desorption $(1 \mathrm{~min})$, the cold trap was rapidly (rate of $40{ }^{\circ} \mathrm{C} \cdot \mathrm{s}^{-1}$ ) heated from $-30{ }^{\circ} \mathrm{C}$ to $300{ }^{\circ} \mathrm{C}$, and maintained at this temperature for $5 \mathrm{~min}$ (secondary desorption). Analytes were then injected onto the capillary column via a transfer line heated at $250 \mathrm{C}$. In our study, the outlet split of the ATD system was fixed to $5 \mathrm{~mL} \mathrm{~min}^{-1}$, enabling $19 \%$ of the trapped analytes to reach the detector. The column oven temperature started at $50{ }^{\circ} \mathrm{C}$ for $5 \mathrm{~min}$, increased to $150{ }^{\circ} \mathrm{C}$ at a rate of $10{ }^{\circ} \mathrm{C} \mathrm{min}-1$, then increased to $280{ }^{\circ} \mathrm{C}$ at a rate of $40{ }^{\circ} \mathrm{C} \mathrm{min}^{-1}$ and was maintained at $280 \mathrm{C}$ for $5 \mathrm{~min}$. Helium carrier gas flow in the analytical column was set to $1.2 \mathrm{~mL} \mathrm{~min}^{-1}$.

Portable GC-PID provided only on-line gas sampling. The analytical method developed by constructor consisted of a 12-minutes-analysis of the 6 BTEX with a constant temperature of $85^{\circ} \mathrm{C}$. The time to load the injection loop $(300 \mu \mathrm{L})$ was $10 \mathrm{~s}$ and the time for the entire filling cycle was $60 \mathrm{~s}$. The total volume distributed through the system was $1.5 \mathrm{~L}$. Nitrogen $(99.999 \%)$ carrier gas flow in the analytical column was $21 \mathrm{~mL} \mathrm{~min}^{-1}$.

\subsection{Sorbent Tube analysis}

With the two ATD-equipped systems, the auto-sampler enables sorbent tube analyses. Thermal primary desorption of the sampling tubes was carried out at $250{ }^{\circ} \mathrm{C}$ with a helium flow rate of 
$25 \mathrm{~mL} \mathrm{~min}{ }^{-1}$ for $20 \mathrm{~min}$ in order to stay in conditions strictly similar to on-line sampling. The outlet split was also fixed to $5 \mathrm{~mL} \mathrm{~min}{ }^{-1}$. The cold trap was maintained at $-30{ }^{\circ} \mathrm{C}$. Again, during secondary desorption, the cold trap was rapidly heated from $-30{ }^{\circ} \mathrm{C}$ to $300{ }^{\circ} \mathrm{C}$ and maintained at this temperature for $5 \mathrm{~min}$. Analytes were then injected onto the capillary column via a transfer line heated at $250{ }^{\circ} \mathrm{C}$ and chromatography conditions were exactly the same as on-line analysis.

\subsection{Preparation and calibration of standard solutions}

On-line calibration curves (10 calibration points) were conducted using the on-line mode of ATD 350. The total sampling volume was $500 \mathrm{~mL}$ and was realized with a reduced sampling flow of

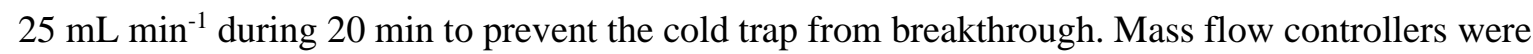
used to dilute the certified BTEX gas mixture in a nitrogen stream.

For liquid sorbent tube calibration, standard solutions were prepared with a certified solution whose initial BTEX concentrations were $100 \mathrm{mg} \mathrm{L}^{-1}$. A stock solution was first prepared by diluting $250 \mu \mathrm{L}$ of commercial mixture into a $25 \mathrm{~mL}$ calibrated flask, and filled with methanol. In order to reduce uncertainty, the added volume of standard was weighed and corrected by solvent density. The solution was further diluted in methanol to obtain BTEX standards ranging from about 0.01 to $2 \mathrm{ng}$ $\mu \mathrm{L}^{-1}$. All standards were freshly prepared.

The calibration curves (10 calibration points) of the BTEX standards were done by spiking 20 $\mu \mathrm{L}$ of the previously prepared standard dilutions into the Carbopack ${ }^{\mathrm{TM}} \mathrm{B}$ sorbent tubes. The calibration points chosen were the same in term of injected amount for both on-line and tube calibrations. The Carbopack ${ }^{\mathrm{TM}} \mathrm{B}$ tubes were thermally conditioned before the spiking step. In order to limit any contamination of the system with the $20 \mu \mathrm{L}$ of solvent deposited on the tube, especially chromatograms profiles, a $50 \mathrm{~mL} \mathrm{~min}^{-1} \mathrm{~N}_{2}$ stream went through the spiked adsorbent cartridge during 10 min: the BTEX compounds were trapped by the adsorbent whereas a large part of methanol was evaporated (see Figure 1). Evaluation of breakthrough volume showed that the overall BTEX were trapped with no losses.

In order to confirm the previous calibration methods, Carbopack ${ }^{\mathrm{TM}} \mathrm{B}$ were also spiked with BTEX gas standard. BTEX concentrations of 2, 10 and $20 \mathrm{ppb}$ were generated from the certified BTEX gas mixture. Mass flow controllers were used to dilute the BTEX gas mixture in a nitrogen stream. Tubes were spiked at $50 \mathrm{~mL} \mathrm{~min}^{-1}$ during $10 \mathrm{~min}$ with a mass flow controller and a pump device. The total volume distributed through the sorbent tube was $500 \mathrm{~mL}$. Note that this third way of calibration was only done for ATD-GC-FID at the 3 mentioned concentrations. The ATD-GC-FID method was used because this is the technique which gives the better reproducibility.

\subsection{Quality assurance parameters}


For quantification of each BTEX, the linearity was evaluated by realizing 10 calibration points and each one was repeated 3 times. For each BTEX compound and for each concentration, reproducibility (inter-day) was expressed using the variation coefficient (VC) derived by the response's standard deviation to average value ratio, converted to a percentage. The highest values of VC were observed for low concentrations, close to detection limit (LOD). For on-line mode, averages VC for all BTEX were $5.2 \%$ for transportable GC-PID, $4.2 \%$ for ATD-GC-FID, 5.5 and $6.6 \%$ for ATD-GC-MS in mode full scan and SIM respectively. For 2-stage-desorb mode (sorbent tubes), averages VC for liquid spiking for all BTEX were 5.1\% for ATD-GC-FID, 5.7 and $7.4 \%$ for ATDGC-MS in mode full scan and SIM respectively. Averages VC for gas spiking are $2.9 \%$ for ATD-GCFID.

The accuracy was evaluated on 3 points; each one was injected 3 times. The method was considered accurate if the recalculated concentration was between 90 and $110 \%$ of the real concentration. We just accepted an accuracy of $20 \%$ for the xylenes isomers quantified with GC-PID because they were not totally resolved (see Figure 2-b). The Limit Of Detection (LOD) was evaluated as 3 times the signal to noise ratio ( $\mathrm{S} / \mathrm{N}=3$ ) and Limit Of Quantification (LOQ) as 10 times the signal to noise ratio $(\mathrm{S} / \mathrm{N}=10)$.

Analytical blank with only nitrogen were realized before each calibration in on-line mode. However, we observed the presence of residual BTEX in the blank, above all toluene. This could be due to residual compounds in the online system or due to small quantities of BTEX in the nitrogen cylinder. These values were taken into account in the calibration curves results. Analytical blank for 2stage-desorb mode were realized with conditioned Carbopack ${ }^{\mathrm{TM}} \mathrm{B}$ tubes spiked with $20 \mu \mathrm{L}$ of methanol for liquid spiking, and with a nitrogen stream for gas spiking.

\section{Results \& Discussion}

\subsection{Comparison of the BTEX separation and time analysis}

The comparison of the ATD-based methods (on-line and 2-stage-desorb modes) shows no great difference in chromatogram profiles. We besides note that there was less than $0.6 \%$ difference in retention times between both injection types confirming the robustness of the analytical method (see Tables 1\&2). Despite the slight difference between the columns composition used for GC-MS and GC-FID, retention times show variation in a range from $0.1 \mathrm{~min}$ to almost $2 \mathrm{~min}$ for benzene and oxylene respectively by using the same increase temperature program and helium gas flow (Figure 2). We therefore consider the two GC methods as comparable confirming that these non-polar columns owned the same performances for BTEX separation. However, because of the composition of the column phase, it was not possible to separate $\mathrm{m}$ - and p-xylenes for both GC so that they were quantified together. 
By contrast transportable GC-PID, which was dedicated to BTEX analysis, was the only one system enabling a partial separation between xylene's isomers because of its polar column composition (see Figure 2). In addition, the complete analysis by GC-PID, taking into account both sampling and GC run, was significantly faster since the 6 BTEX compounds were separated in less than $12 \mathrm{~min}$ instead of $43.25 \mathrm{~min}$ (20 min sampling $+23.25 \mathrm{~min}$ for chromatographic run) for the ATD-based methods.

\subsection{Comparison of analytical techniques: on-line analysis}

\section{Linearity of calibrations plots}

The calibration curves derived from on-line analysis for all 6 BTEX (Figure 3) have globally denoted a good linearity for all analytical methods. However the linearity was quite biased for low concentrations constraining us to elaborate two calibration curves for all analytical instruments: one for low injected quantities between 0 to 4 ng range corresponding to $0-2 \mathrm{ppb}$ range and one for higher injected quantities 4 to $50 \mathrm{ng}$ corresponding to $2-20 \mathrm{ppb}$ range (see Table 1). Despite a specific fit at low concentrations, correlation coefficients $\mathrm{R}^{2}$ ranged from 0.969 to 0.990 for ATD-GC-FID, from 0.975 to 0.996 for ATD-GC-MS in full scan mode, and from 0.978 to 0.995 for ATD-GC-MS in SIM mode whereas calibration curves for the 4-50 ng range gave $\mathrm{R}^{2}$ values from 0.996 to 1 . We noted that $\mathrm{R}^{2}$ values derived from the GC-PID are near from 1 for the two ranges with values ranging from 0.997 to 0.999 for the 0 to $4 \mathrm{ng}$ range and from 0.991 to 0.998 for the $4-50 \mathrm{ng}$ range. In addition, Table 1 exhibits that calibration curve slopes values for GC-PID are quite similar between low and high concentrations ranges which was not the case for all ATD-based methods. In order to explain this observation, it has been assumed that on-line mode tubing was easily polluted resulting in impurities apparition on the chromatograms. The interfering peaks were more limited in the case of the GC-PID (compared to FID or MS in full-scan mode) since this latter is equipped with a specific detector of unsaturated VOCs and a specific column optimized for the separation of aromatic VOCs $[13,36]$. Nevertheless, it was then difficult to be very accurate when quantifying low concentrations. Besides, it remains possible that some BTEX residues are present in the $\mathrm{N}_{2}$ gas cylinder used for dilution as previously observed by Liu et al.[36]. As all analytical blanks were realized with the same nitrogen cylinder, uncertainties for low BTEX concentrations could be explained. Indeed, figure 2.e) shows that impurities of the blank mainly interfere with benzene and above all toluene.

If the analytical criterion is linearity for the ATD-GC systems, on-line mode is then probably more appropriated to analyze concentrations higher than ppb level. Conversely, by taking into account the linearity as the only one analytical criterion, the GC-PID seems to be the most suitable to quantify concentrations between $0.1 \mathrm{pg}$ and $50 \mathrm{ng}$ for benzene and $0.2 \mathrm{pg}$ and $50 \mathrm{ng}$ for the other BTEX, i.e. on the entire range of investigated concentrations (see LOD range in Table 1). 


\section{Limits Of Detection}

Table 1 reports all LOD values in ppb which have been also converted to micrograms per cubic meter $\left(\mu \mathrm{g} \mathrm{m}^{-3}\right)$ and to injected quantities in picograms (pg). Considering these LOD values, differences in sensitivity between the various ATD-based methods and the mobile GC-PID were observed. From a general point of view, the results show that LOD values are directly related to the analyzed compounds and their response with respect to the detector but also related to the potential presence of impurities.

When comparing LOD in pg, the transportable GC-PID is much more sensitive since it needs only a tiny quantity of each BTEX to detect them with an average value of $0.2 \mathrm{pg}$ injected and only $0.06 \mathrm{pg}$ for benzene which is remarkably lower than those determined for other ATD-based methods : 3-16 pg (ATD-GC-MS, SIM mode), 20-94 pg (ATD-GC-MS, Full Scan mode) and 81-190 pg (ATDGC-FID).

However, the comparison of analytical methods in terms of sensitivity can be highly different depending on the considered LOD, i.e. the detected quantity (in pg) or the detected concentration (ppb). Indeed, the sampled volume is highly different between ATD-based method (500 mL) and GCPID (injection loop of $300 \mu \mathrm{L}$ ). In terms of sensitivity to air pollutants, it is more consistent to express the LOD of a given technique in ppb (or in $\mu \mathrm{g} \mathrm{m}^{-3}$ ). That's why a more detailed comparison of LOD in ppb is given below.

First, the comparison of all ATD-based methods shows, as expected, that the ATD-GC-MS in SIM mode is the most sensitive method with LOD ranging from $2 \mathrm{ppt}$ for Toluene and o-Xylene to 7 ppt for Benzene and Ethylbenzene. The LOD are significantly higher, varying in the ranges 9-42 ppt and 42-86 ppt for ATD-GC-MS in Full Scan Mode and ATD-GC-FID, respectively. The FID stayed therefore the less sensitive detector in agreement with literature $[13,14,21]$.

Then, the LOD obtained by GC-PID is 58 ppt for benzene while they are significantly higher for other compounds with ranges between 108 and 234 ppt. For benzene, this LOD is 8 times higher than that found for ATD-GC-MS in SIM mode but it is approximately $30 \%$ lower than the value of 85 ppt determined for ATD-GC-FID. Taking account the volume of sampling air which is about 1670 times lower in the case of GC-PID, such a detection limit obtained for GC-PID is remarkably low. The same comparison is less in favor of GC-PID if the other BTEX are considered.

Besides, it is possible to decrease the limits of detection for ATD-based methods by increasing the sampling volume going through the focusing cold trap. Consequently, for a given sampling flow rate the sampling time will increase. Figure 4 shows that peak's area for benzene and $\mathrm{m} / \mathrm{p}$-xylenes increase linearly ( $\mathrm{R}^{2}$ of 0.999 for both species) with the sampling volume, whatever the sampling flow applied. Therefore, it could be suggested to increase the sampling time (and therefore the sampling volume) in order to detect small gaseous BTEX concentrations [41]. Another way to enhance the signal at smaller concentrations and so to decrease the LOD, is to modify the outlet split parameter on the ATD device. Histograms in Figure 5 represent some tests, performed with ATD-GC-MS, to 
evaluate the area enhancement when decreasing the outlet split. The Figure 5.a) shows that area increases when the outlet split decreases. Figure 5.b) represents the calculated area to dilution factor ratio caused by outlet split. Whatever the outlet split chosen, the same ratio is observed for each compound showing good regulation and reproducibility of the split flow. Therefore, the ATD split function is also a reliable way to enhance the response when the gaseous concentrations are low. With regards on these results, decreasing the LOD on ATD-based systems is possible by working for instance at sampling volume of 1 liter or more [33-35,42] or with an outlet split of $2 \mathrm{~mL} \mathrm{~min}^{-1}$. This latter is however not recommended because it is most appropriate to use a high outlet split in order to maintain helium flow as high as possible during trap's heating and desorption [16]. However, with environmental samples, decreasing the outlet split could saturate the column with the presence of other compounds that can be present in air at higher concentrations than BTEX. Generally, toluene is the higher concentrated VOC in outdoor air, but other compounds could also be found at higher concentrations. Hence, before decreasing outlet split, it could be of interest to evaluate some proof samples in order to determine if this change could affect the analysis.

\subsection{Comparison between ATD injection modes: on-line and 2-stage-desorb}

This part aims to highlight that the sorbent tubes analysis is also a good alternative to realize calibration curves. This type of analysis is often used especially when organic compounds are not commercially available in gas phase.

\section{Linearity of calibrations plots}

Calibration curves obtained by spiking liquid BTEX standard on Carbopack ${ }^{\mathrm{TM}}$ B sorbent tubes are reported in Table 2. To be consistent with the analytic treatment realized for on-line injection mode, two calibration curves were fitted, one for the 0-4 ng range and one for the 4-50 ng range, even if the slope differences were smaller. The slope values determined for the two concentrations ranges were very close suggesting that a global fit could be justified, except for benzene and toluene with ATD-GC-FID analysis. This latter observation can be explained by the presence of numerous and important impurities from methanol (blank) co-eluting with benzene especially and toluene (see Figure 2.f). Since these two peaks are determined using the valley to valley integration, this resulted in a larger uncertainty on the area of these two compounds explaining why, for liquid spiking, these two calibration curves are located under the on-line calibration curves, which was not the case for the other compounds (see Figure 6).

For all BTEX compounds, the calibration curves derived from both injection modes in ATDGC-FID represented in Figure 6 are in excellent agreement for concentrations between 4-50 ng even if a small shift can be identified for benzene for the reason explained above. These results have been 
confirmed by realizing a 3-points calibration curve where gaseous BTEX were initially spiked on a Carbopack ${ }^{\mathrm{TM}} \mathrm{B}$ cartridge and further analyzed in GC-FID with the 2-stage-desorb mode of ATD (see Figure 6). Both gas spiking and on-line curves show a perfect agreement for the 3 investigated high concentrations. By contrast with on-line calibrations, a good linearity for the 2-stage-desorb mode is observed even for low concentrations for liquid or gas spiking. As a consequence, 2-stage-desorb mode seems to be more appropriate to quantify BTEX level exposure at sub-ppb level. For instance, to monitor benzene in indoor air and especially with regard to its European Commission guideline, it is preferable to sample air on cartridges than in canisters and to perform calibration with liquid cartridge spiking to determine precisely if the recommended limit of exposure of $1.6 \mathrm{ppb}$ is respected.

\section{Limits Of Detection}

The results summarized in Table 2confirm all the conclusions mentioned above for on-line injection mode concerning the detectors. ATD-GC-MS in SIM mode with LOD varying between 2 and $12 \mathrm{pg}$ depending on the compound is significantly more sensitive than the two others, i.e. ATDGC-MS in full scan mode (32 - $207 \mathrm{pg}$ ) and ATD-GC-FID (106 - 164 pg).

Again, the higher LOD for benzene and toluene can be explained by the presence of impurities from methanol (blank) co-eluting with these two species when analysis was performed by either ATD-GC-FID or ATD-GC-MS in full scan mode. Interfering peaks were minimized when the analysis was realized by ATD-GC-MS in SIM mode because detection was done on one specific ion for benzene and toluene which was probably absent in the impurities mass spectra. In addition, the higher LOD for ATD-GC-FID and MS in full scan mode could also come from a lower sensitivity of the method using scan.

The LOD (in pg) obtained in 2-stage-desorb injection mode are in the same order of magnitude than those determined in on-line injection mode (in brackets) : ATD-GC-FID, 106 - 163 pg (81 - 190 pg); ATD-GC-MS in full scan, 32 - 207 pg (19 - 93 pg); ATD-GC-MS in SIM mode, 2 - 12 pg $(3-16 \mathrm{pg})$.

\section{Conclusion}

This study compared the performances of several analytical techniques applied to the quantification of the BTEX mixture in air. One technique was a transportable GC-PID. The two others are ATD-based systems coupled to either a GC-FID or a GC-MS.

This study reveals that the transportable GC-PID is the most sensitive technique when the injected amount (in pg) of sample is considered. GC-PID allows also an efficient separation and quantification of the 6 BTEX compounds in $12 \mathrm{~min}$.

However, the ATD-based systems permit to reach comparable or better LOD in ppb than those determined by GC-PID (58 ppt for benzene for example) when their air sampling volume reaches 500 
$\mathrm{mL}$, as illustrated for benzene in on-line mode (in units of ppt): 85 (ATD-GC-FID), 22 (ATD-GC-MS in full scan mode), 7 (ATD-GC-MS in SIM mode). It is also the case in 2-stage-desorb injection mode where LOD of benzene is found to be equal to $10 \mathrm{ppt}$ (ATD-GC-FID), $11 \mathrm{ppt}$ (ATD-GC-MS in full scan mode) and 7 ppt (ATD-GC-MS in SIM mode). Finally, all the investigated techniques permit to reach the targeted concentration of $1.6 \mathrm{ppb}$ for benzene in European indoor environments. In addition, the sampling of low volumes is more sensitive to presence of impurities and results in higher LOD values. Therefore, the sensitivity of ATD-based methods can be enhanced by increasing the sampling volume or decreasing the outlet split of the device. Note that GC-FID showed less variability than GCPID and above all GC-MS resulting in achieving quantification on FID and qualitative analysis on MS detector even if using both methodologies to analyze BTEX is more time consuming.

Although sensitivity is a choice criteria there are other ways to characterize performances of these analytical instruments. As specified in introduction, transportable analyzers are sensitive and effective but only for a few compounds. Besides, they are often heavy and need some supply. ATDbased systems are of course more time-consuming techniques but potentially allow analysis of several tens of compounds in a single run. Furthermore, the ATD-based systems enable on-line sampling, the use of adsorbent cartridge or canister as collection media for air sampling. They can be directly analyzed thanks to the ATD unit avoiding sample preparation and therefore any eventual analytes losses.

Finally, this study revealed that cartridge spiking is an appropriate alternative to on-line analysis especially to quantify BTEX at sub-ppb level. Then, liquid cartridge spiking allows the use of liquid references that are easier to provide and have mostly a less important relative error on concentration than gas cylinder references. 


\section{References}

[1] G. Demirel, Ö. Özden, T. Döğeroğlu, E.O. Gaga, Personal exposure of primary school children to BTEX, NO2 and ozone in Eskişehir, Turkey: Relationship with indoor/outdoor concentrations and risk assessment, Sci. Total Environ. 473-474 (2014) 537-548.

doi:10.1016/j.scitotenv.2013.12.034.

[2] C.W. Sweet, S.J. Vermette, Toxic volatile organic compounds in urban air in Illinois, Environ. Sci. Technol. 26 (1992) 165-173. doi:10.1021/es00025a020.

[3] H. Guo, S.C. Lee, W.M. Li, J.J. Cao, Source characterization of BTEX in indoor microenvironments in Hong Kong, Atmos. Environ. 37 (2003) 73-82. doi:10.1016/S13522310(02)00724-0.

[4] L.A. Wallace, E. Pellizzari, B. Leaderer, H. Zelon, L. Sheldon, Emissions of volatile organic compounds from building materials and consumer products, Atmospheric Environ. 1967. 21 (1987) 385-393. doi:10.1016/0004-6981(87)90017-5.

[5] S. Sollinger, K. Levsen, G. Wünsch, Indoor air pollution by organic emissions from textile floor coverings. Climate chamber studies under dynamic conditions, Atmospheric Environ. Part B Urban Atmosphere. 27 (1993) 183-192. doi:10.1016/0957-1272(93)90004-P.

[6] J.L. Adgate, L.E. Eberly, C. Stroebel, E.D. Pellizzari, K. Sexton, Personal, Indoor, and Outdoor VOC Exposures in a Probability Sample of Children, J. Expo. Sci. Environ. Epidemiol. 14 (2004) S4-S13. doi:10.1038/sj.jea.7500353.

[7] E. Ortiz, E. Alemón, D. Romero, J.L. Arriaga, P. Olaya, F. Guzmán, et al., Personal exposure to benzene, toluene and xylene in different microenvironments at the Mexico City metropolitan zone, Sci. Total Environ. 287 (2002) 241-248.

[8] WHO, Regional Office for Europe, Benzene. In: Air Quality Guidelines for Europe (2nd ed.). Copenhagen, World Health Organization Regional Office for Europe, (2000).

[9] V. Simon, M. Baer, L. Torres, S. Olivier, M. Meybeck, J.P. Della Massa, The impact of reduction in the benzene limit value in gasoline on airborne benzene, toluene and xylenes levels, Sci. Total Environ. 334-335 (2004) 177-183. doi:10.1016/j.scitotenv.2004.04.065.

[10] T.T.N. Lan, P.A. Minh, BTEX pollution caused by motorcycles in the megacity of HoChiMinh, J. Environ. Sci. China. 25 (2013) 348-356.

[11] P. Schneider, I. Gebefügi, K. Richter, G.W. Wölke, J. Schneille, H.E. Wichmann, et al., Indoor and outdoor BTX levels in German cities, Sci. Total Environ. 267 (2001) 41-51.

[12] E. Gallego, F.X. Roca, X. Guardino, M.G. Rosell, Indoor and outdoor BTX levels in Barcelona City metropolitan area and Catalan rural areas, J. Environ. Sci. China. 20 (2008) 1063-1069.

[13] R.M. Cavalcante, M.V.F. de Andrade, R.V. Marins, L.D.M. Oliveira, Development of a headspace-gas chromatography (HS-GC-PID-FID) method for the determination of VOCs in environmental aqueous matrices: Optimization, verification and elimination of matrix effect and VOC distribution on the Fortaleza Coast, Brazil, Microchem. J. 96 (2010) 337-343. doi:10.1016/j.microc.2010.05.014.

[14] H.S. Dórea, J.R.L. Bispo, K.A.S. Aragão, B.B. Cunha, S. Navickiene, J.P.H. Alves, et al., Analysis of BTEX, PAHs and metals in the oilfield produced water in the State of Sergipe, Brazil, Microchem. J. 85 (2007) 234-238. doi:10.1016/j.microc.2006.06.002.

[15] E. Woolfenden, Monitoring VOCs in Air Using Sorbent Tubes Followed by Thermal Desorption-Capillary GC Analysis: Summary of Data and Practical Guidelines, J. Air Waste Manag. Assoc. 47 (1997) 20-36. doi:10.1080/10473289.1997.10464411.

[16] E. Woolfenden, Chapter 10 - Thermal Desorption for Gas Chromatography, in: Gas Chromatogr., Elsevier, Amsterdam, 2012: pp. 235-289.

[17] A. Allouch, S. Le Calvé, C.A. Serra, Portable, miniature, fast and high sensitive real-time analyzers: BTEX detection, Sens. Actuators B Chem. 182 (2013) 446-452. doi:10.1016/j.snb.2013.03.010.

[18] J. Ji, C. Deng, W. Shen, X. Zhang, Field analysis of benzene, toluene, ethylbenzene and xylene in water by portable gas chromatography-microflame ionization detector combined with headspace solid-phase microextraction, Talanta. 69 (2006) 894-899.

doi:10.1016/j.talanta.2005.11.032. 
[19] F.L. Dorman, J.J. Whiting, J.W. Cochran, J. Gardea-Torresdey, Gas Chromatography, Anal. Chem. 82 (2010) 4775-4785. doi:10.1021/ac101156h.

[20] R.-S. Jian, Y.-S. Huang, S.-L. Lai, L.-Y. Sung, C.-J. Lu, Compact instrumentation of a $\mu$-GC for real time analysis of sub-ppb VOC mixtures, Microchem. J. 108 (2013) 161-167. doi:10.1016/j.microc.2012.10.016.

[21] J. Koziel, M. Jia, A. Khaled, J. Noah, J. Pawliszyn, Field air analysis with SPME device, Anal. Chim. Acta. 400 (1999) 153-162. doi:10.1016/S0003-2670(99)00614-5.

[22] S. Król, B. Zabiegała, J. Namieśnik, Monitoring VOCs in atmospheric air I. On-line gas analyzers, TrAC Trends Anal. Chem. 29 (2010) 1092-1100. doi:10.1016/j.trac.2010.05.007.

[23] Baseline-Mocon, Series 8900GC Application Note_BTEX in Ambient Air using a HighSensitivity PID, (n.d.).

[24] Environnement S.A, Analyseur de Composés Organiques Volatils (BTEX) par Chromatographie Gazeuse VOC72M, (n.d.).

[25] E. Woolfenden, Sorbent-based sampling methods for volatile and semi-volatile organic compounds in air: Part 1: Sorbent-based air monitoring options, J. Chromatogr. A. 1217 (2010) 2674-2684. doi:10.1016/j.chroma.2009.12.042.

[26] I.E. Galbally, R.W. Gillett, J.C. Powell, S.J. Lawson, S.T. Bentley, I.A. Weeks, Household wood heater usage and indoor leakage of BTEX in Launceston, Australia: A null result, Atmos. Environ. 43 (2009) 2788-2795. doi:10.1016/j.atmosenv.2009.02.035.

[27] E. Rodolfo Sosa, A. Humberto Bravo, A. Violeta Mugica, A. Pablo Sanchez, L. Emma Bueno, S. Krupa, Levels and source apportionment of volatile organic compounds in southwestern area of Mexico City, Environ. Pollut. Barking Essex 1987. 157 (2009) 1038-1044. doi:10.1016/j.envpol.2008.09.051.

[28] Compendium Method TO-14.,U.S. Environmental Protection Agency: Research Triangle Park, NC, Compendium Method TO-14."The Determination of VOCs in Ambient Air Using Summa, Passivated Canister Sampling and GC Analysis," (1988).

[29] M.R. Ras, F. Borrull, R.M. Marcé, Sampling and preconcentration techniques for determination of volatile organic compounds in air samples, TrAC Trends Anal. Chem. 28 (2009) 347-361. doi:10.1016/j.trac.2008.10.009.

[30] C.-H. Wu, C.-T. Feng, Y.-S. Lo, T.-Y. Lin, J.-G. Lo, Determination of volatile organic compounds in workplace air by multisorbent adsorption/thermal desorption-GC/MS, Chemosphere. 56 (2004) 71-80. doi:10.1016/j.chemosphere.2004.02.003.

[31] E. Gallego, F.J. Roca, J.F. Perales, G. Sánchez, P. Esplugas, Characterization and determination of the odorous charge in the indoor air of a waste treatment facility through the evaluation of volatile organic compounds (VOCs) using TD-GC/MS, Waste Manag. 32 (2012) 2469-2481. doi:10.1016/j.wasman.2012.07.010.

[32] E. Gallego, F.J. Roca, J.F. Perales, X. Guardino, Comparative study of the adsorption performance of a multi-sorbent bed (Carbotrap, Carbopack X, Carboxen 569) and a Tenax TA adsorbent tube for the analysis of volatile organic compounds (VOCs), Talanta. 81 (2010) 916924. doi:10.1016/j.talanta.2010.01.037.

[33] M. de Blas, M. Navazo, L. Alonso, N. Durana, J. Iza, Automatic on-line monitoring of atmospheric volatile organic compounds: Gas chromatography-mass spectrometry and gas chromatography-flame ionization detection as complementary systems, Sci. Total Environ. 409 (2011) 5459-5469. doi:10.1016/j.scitotenv.2011.08.072.

[34] M. Sarkhosh, A.H. Mahvi, M.R. Zare, Y. Fakhri, H.R. Shamsolahi, Indoor contaminants from Hardcopy Devices: Characteristics of VOCs in photocopy centers, Atmos. Environ. 63 (2012) 307-312. doi:10.1016/j.atmosenv.2012.09.058.

[35] X. Wang, G. Sheng, J. Fu, C. Chan, S.-C. Lee, L.Y. Chan, et al., Urban roadside aromatic hydrocarbons in three cities of the Pearl River Delta, People's Republic of China, Atmos. Environ. 36 (2002) 5141-5148. doi:10.1016/S1352-2310(02)00640-4.

[36] K. Liu, J. Quan, Y. Mu, Q. Zhang, J. Liu, Y. Gao, et al., Aircraft measurements of BTEX compounds around Beijing city, Atmos. Environ. 73 (2013) 11-15. doi:10.1016/j.atmosenv.2013.02.050. 
[37] J. Sun, F. Guan, D. Cui, X. Chen, L. Zhang, J. Chen, An improved photoionization detector with a micro gas chromatography column for portable rapid gas chromatography system, Sens. Actuators B Chem. 188 (2013) 513-518. doi:10.1016/j.snb.2013.07.066.

[38] L.M.L. Nollet, Chromatographic Analysis of the Environment, Third Edition, third edition, CRC Press, 2005.

[39] U. Wideqvist, V. Vesely, C. Johansson, A. Potter, E. Brorström-Lundén, K. Sjöberg, et al., Comparison of measurement methods for benzene and toluene, Atmos. Environ. 37 (2003) 1963-1973. doi:10.1016/S1352-2310(03)00029-3.

[40] N.A. Martin, D.J. Marlow, M.H. Henderson, B.A. Goody, P.G. Quincey, Studies using the sorbent Carbopack X for measuring environmental benzene with Perkin-Elmer-type pumped and diffusive samplers, Atmos. Environ. 37 (2003) 871-879. doi:10.1016/S1352-2310(02)01000-2.

[41] J. Roukos, H. Plaisance, T. Leonardis, M. Bates, N. Locoge, Development and validation of an automated monitoring system for oxygenated volatile organic compounds and nitrile compounds in ambient air, J. Chromatogr. A. 1216 (2009) 8642-8651. doi:10.1016/j.chroma.2009.10.018.

[42] C. Park, G.W. Schade, I. Boedeker, Flux measurements of volatile organic compounds by the relaxed eddy accumulation method combined with a GC-FID system in urban Houston, Texas, Atmos. Environ. 44 (2010) 2605-2614. 


\section{Tables}

Table 1. Calibration parameters for the 4 methods in on-line injection mode

Table 2. Calibration parameters for the 3 methods using liquid spiking in 2-stage-desorb injection mode. 


\section{Figure legend}

Figure 1.Scheme of the analytical procedure for the adsorbent tube spiking.

Figure 2. Chromatograms of BTEX sample: (a) On-line analysis of 5 ppb BTEX sample with ATDGC-FID. (b) On-line analysis of 5 ppb BTEX sample in Full-scan mode with ATD-GC-MS. (c) Analysis of 5 ppb BTEX sample with portable GC-PID. (d) On-line analysis of 5 ppb BTEX sample in SIM mode with ATD-GC-MS. (e) Superposition of a 2 ppb BTEX on-line sample (black line) and an on-line N2 blank analysis (gray line) with ATD-GC-FID. (f) 2-stage-desorb injections: superposition of a 4 ng BTEX spiked liquid standard (black line) and an injection of $20 \mu \mathrm{L} \mathrm{MeOH}$ spiked (gray line).

1. Benzene, 2. Toluene, 3. Ethylbenzene, 4. p-Xylene, 5. m-Xylene, 6. o-Xylene.

Figure 3.Calibration curves for on-line mode for the 6 BTEX. The left plot corresponds to 4-50 ng range while the right scale is the calibration curve obtained for low concentrations ( $0-4 \mathrm{ng}$ range): (a) ATD-GC-FID, (b) ATD-GC-MS in full scan mode, (c) ATD-GC-MS in SIM mode, (d) Portable GCPID.

*Concentrations in $\mu \mathrm{g} \mathrm{m}^{-3}$ for a sampled volume of $500 \mathrm{~mL}$

Figure 4.Evolution of the response in ATD-GC-FID (on-line mode) with the sampling volume for Benzene and $\mathrm{m}+\mathrm{p}$-Xylenes : two sampling flows (Fspl) tested, $25 \mathrm{~mL} \mathrm{~min}^{-1}$ and $50 \mathrm{~mL} \mathrm{~min}^{-1}$.

Figure 5. Variation of the outlet split in ATD-GC-MS (on-line mode, full scan detection) to enhance the response area with a 5 ppb BTEX sample (approximately $18 \mu \mathrm{g} \mathrm{m}^{-3}$ for benzene, $22 \mu \mathrm{g} \mathrm{m}^{-3}$ for toluene, $23 \mu \mathrm{g} \mathrm{m}^{-3}$ for ethylbenzene, $24 \mu \mathrm{g} \mathrm{m}^{-3}$ for xylenes) : (a) Response area with varying outlet split,(b) Area normalized by dilution factor.

Figure 6.Comparison between calibration curves obtained in ATD-GC-FID for on-line and for 2-stagedesorb injection modes. The left plot corresponds to 4-50 ng range while the right scale is the calibration curve obtained for low concentrations (0-4 ng range). The black solid line is the linear regression for online mode, the gray line for gaz spiking and the dotted line for liquid spiking:

(a) Benzene, (b) Toluene,(c) Ethylbenzene, (d) m+p-Xylenes,(e) o-Xylene

*Concentrations in $\mu \mathrm{g} \mathrm{m}^{-3}$ for a sampled volume of $500 \mathrm{~mL}$ 